\title{
The immune tumour microenvironment of neuroendocrine tumours and its implications for immune checkpoint inhibitors
}

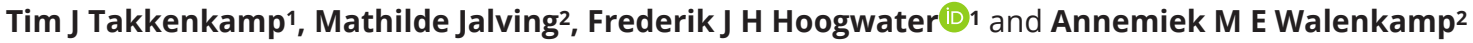 \\ 1Department of Surgery, University Medical Center Groningen, University of Groningen, Groningen, The Netherlands \\ 2Department of Medical Oncology, University Medical Center Groningen, University of Groningen, Groningen, The Netherlands
}

Correspondence should be addressed to A M E Walenkamp: a.walenkamp@umcg.nI

\begin{abstract}
Immunotherapy in the form of immune checkpoint inhibitors (ICls) has transformed the treatment landscape in numerous types of advanced cancer. However, the majority of patients do not benefit from this treatment modality. Although data are scarce, in general, patients with low-grade neuroendocrine tumours (NETs) do not benefit from treatment with ICls in contrast to patients with neuroendocrine carcinoma, in which a small subgroup of patients may benefit. Low- and intermediate-grade NETs predominantly lack factors associated with response to ICls treatment, like immune cell infiltration, and have an immunosuppressive tumour metabolism and microenvironment. In addition, because of its potential influence on the response to ICls, major interest has been shown in the tryptophan-degrading enzymes indoleamine 2,3-dioxygenase (IDO) and tryptophan 2,3-dioxygenase (TDO). These enzymes work along the kynurenine pathway that deplete tryptophan in the tumour microenvironment. IDO and TDO are especially of interest in NETs since some tumours produce serotonin but the majority do not, which potentially deplete the precursor tryptophan. In this review, we summarize the current knowledge on the immune tumour microenvironment of neuroendocrine tumours and implications for treatment with immune checkpoint inhibitors. We also discuss (targetable) factors in the NET tumour microenvironment that potentially modulate the anti-cancer immune response.
\end{abstract}

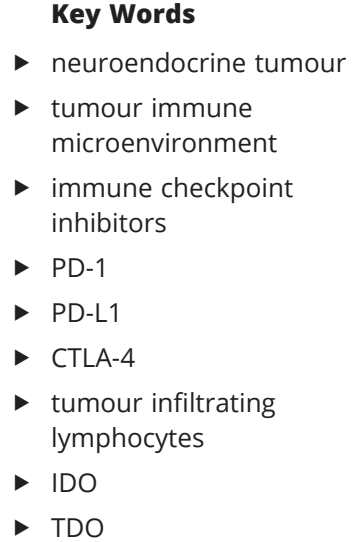

\section{Introduction}

NETs are tumours that arise from epithelial cells with both neurological and endocrinological functions and are most commonly located in the gastro-intestinal (GI) tract (https://www.cancer.net/cancer-types/neuroendocrinetumors/introduction). NETs can be divided into two types: symptomatic, due to biogene amine overproduction, or non-symptomatic. The 2017 WHO classification further subdivides NETs into four separate categories: Grade 1, 2 and 3 well-differentiated NETs and grade 3 poorly differentiated neuroendocrine carcinomas (NECs) (Kim et al. 2017). Next to this, a study analysing gastric carcinomas found that $10 \%$ of these tumours are neuroendocrine malignant tumours and were reclassified as NECs (Waldum et al. 1998). The incidence of neuroendocrine tumours in adult patients is 6.98 per 100,000 people, according to the 2012 Surveillance, Epidemiology, and End Results (SEER) data, and this number is increasing (Dasari et al. 2017). Median overall survival of all patients with NETs 
is 9.3 years (Dasari et al. 2017). However, there is large variation depending on tumour location, stage and grade (Dasari et al. 2017). Surgical resection is the only potentially curative option. Palliative treatment options that aim at controlling symptoms and reducing tumour growth are available and include somatostatin analogues, everolimus, sunitinib, peptide receptor radionuclide therapy (PRRT), interferon and chemotherapy. (Pavel et al. 2012, Phan et al. 2015). The tumour microenvironment (TME) in cancer is recognized as a critical participant in determining tumour biology. Components of the TME include surrounding blood vessels, immune cells, fibroblasts, signalling molecules and the extracellular matrix. In this environment, T cells potentially have the capacity to selectively recognize cancer cells and generate a coordinated immune response. Cancer cells use immune checkpoints to escape recognition by $\mathrm{T}$ cells, thereby preventing an adequate anti-tumour immune response. Monoclonal antibodies that target immune checkpoint proteins, including programmed cell death-1 (PD-1, e.g. nivolumab), programmed cell death ligand -1 (PD-L1, e.g. atezolizumab) and cytotoxic T lymphocyte-associated antigen-4 (CTLA-4, e.g. ipilimumab), can restore the antitumour immune response (Herbst et al. 2014, Sivan et al. 2015, Vetizou et al. 2015). Treatment approaches involving CTLA-4 and PD-1/PDL-1 inhibition have successfully improved patient outcomes across various tumour types. However, even in immune-sensitive tumour types, a wide variety of patients do not achieve long-term benefit and factors involved in both primary and secondary resistance have been identified (Blank et al. 2016, Chen \& Mellman 2017, Seto et al. 2019). Clinical data on the effectivity of ICIs in NETs is scarce and the results are inconsistent (Schmidt \& Wiedenmann 2018, Weber \& Fottner 2018). In this review, we summarize the current knowledge on effectivity of checkpoint inhibition in NETs and discuss (targetable) factors in the NETs TME that potentially modulate the anti-cancer immune response.

\section{Mechanism of action of immune checkpoint inhibitors}

ICIs work by interrupting the PD-1 and PDL-1 or CTLA-4 pathway resulting in disinhibition of the tumour evasion mechanisms and thereby enabling $\mathrm{T}$ cells to recognize tumour cells and destroy them. Physiologically, PD-1 expression has its role in preventing unnecessary immune responses in peripheral tissues preventing autoimmunity and promoting immune tolerance (Dorfman et al. 2006,
Raimondi et al. 2006). PD-1 is a tyrosine-based inhibitory motif (ITIM)-containing receptor expressed on T cells and interacts with PDL-1 (B7-H1, CD274) and PDL-2 (B7-DC, CD273). Stimulation of the PD-1 receptor typically has greater effects on cytokine production than on cellular proliferation, with significant effects on IFN- $\gamma$, TNF- $\alpha$, and IL-2 production. Interaction of PD-L1 expressed on tumours with PD-1 on immune cells prevents activation of cytotoxic T cells (CTCs) and results in downregulation of cytotoxic cytokine production (Rudd et al. 2009). CTLA-4 mediates immunosuppression by reducing signalling through the co-stimulatory receptor CD28 and thereby its interaction with B7 on antigen presenting cells (APC) (Rudd et al. 2009). Despite its structural similarity to CD28, CTLA-4 has an opposing effect on T-cell immunity by dampening or actively inhibiting T-cell activation (Rudd et al. 2009). CTLA-4 is a homologue of CD28 that has a much higher binding affinity for B7 expressed on antigen presenting cells (APC) but does not produce a stimulatory signal. As such, this competitive binding can prevent the co-stimulatory signal normally provided by CD28:B7 binding. The relative amount of CD28:B7 binding vs CTLA-4:B7 binding determines whether a $\mathrm{T}$ cell will undergo activation or anergy (Chambers et al. 2001, Greenwald et al. 2005).

Treatment with ICIs results in increased progressionfree survival (PFS) and overall survival (OS) with subgroups of patients achieving long term survival. For example, in the phase 3 trial (CheckMate 067) in patients with advanced melanoma, the median OS was more than 60.0 months (median not reached) in the nivolumab-plusipilimumab group and 36.9 months in the nivolumab group, as compared with 19.9 months in the ipilimumab group. Before the introduction of ICIs, almost all patients died within 2 years of diagnosis (Larkin et al. 2019). ICIs have also revolutionised the approach to metastatic NSCLC with single-agent ICIs treatment. ICIs are now the standard of care in the first-line setting in patients with metastatic non-oncogene addicted NSCLC, either alone or in combination with chemotherapy (Vansteenkiste et al. 2019). Furthermore, until 2020, the Food and Drug Administration (FDA) has approved ICIs for the treatment of renal cell carcinoma, urothelial and bladder cancer, head and neck squamous-cell carcinoma, metastatic Merkel cell carcinoma, refractory classical Hodgkin lymphoma, microsatellite instability-high cancers (MSI), and gastric cancer (Emens et al. 2017, Wolchok et al. 2017, Motzer et al. 2018, Ward et al. 2018, Luchini et al. 2019). Despite unprecedented responses, not all patients respond to treatment with ICIs. 


\section{Effectivity of immune checkpoint inhibitors in NET and NEC}

Data on response to ICIs in NETs are scarce and inconsistent. KEYNOTE-028 is a single-arm, phase $1 \mathrm{~b}$, basket trial that evaluated pembrolizumab (PD-1 inhibitor) in 20 cohorts of patients with a range of advanced solid tumours positive for PD-L1 who had not responded to previous therapies. In this trial, 41 patients with wellor moderately differentiated NETs were included; the primary sites were lung, $n=9$; gut, $n=7$; other, $n=9$; and pancreas, $n=16$. Four patients showed objective responses and 29 patients had at least stable disease for more twhan 6 months (Mehnert et al. 2017). Based on these results, the phase II basket trial, KEYNOTE-158, was designed to evaluate pembrolizumab in ten different tumour types, including 107 patients with NETs. NETs originating from pancreas, small intestine, and lung were included. Twothirds of patients had received at least two prior therapies and $16 \%$ expressed PD-L1. After a median follow-up of 18.6 months, the overall response rate was $3.7 \%$, with no complete responses and four partial responses, including three responses in patients with a neuroendocrine tumour of the pancreas and one in a patient with a gastrointestinal NETs (GI NETs). Three of the four patients that responded had a histologically grade 2 NETs. The tumour of one patient was a low-grade pancreatic NETs with aggressively progressive disease at the time of study enrolment. The median PFS was 4.1 months and the 6-month PFS rate was $38 \%$. The median duration of response and median overall survival were not reached, and at 6 months, $85 \%$ of patients were alive. Three of the four responses were ongoing after at least 9 months. None of four patients with responses to pembrolizumab had expression of PD-L1 (Ott et al. 2019, Strosberg et al. 2019).

A small phase II clinical trial including 29 patients with metastatic grade 3 NECs $(n=16)$ and moderately differentiated grade 3 NETs $(n=11)$ reported on the efficacy and safety of Avelumab (PD-L1 inhibitor) treatment. Site of origin included pancreas $(n=12)$, genito-urinary tract $(n=4)$, stomach-oesophagus $(n=3)$, colo-rectum $(n=3)$, lung $(n=2)$, ear-nose-throat $(n=2)$, papilla of Vater $(n=1)$. In responders, mean duration of disease control was 20 weeks, with four patients showing stable disease or partial remission $\geq 6$ months. Median OS was 4.2 months (range 1-12 months) (Fottner et al. 2019). Another prospective phase II basket trial (DART) investigating the combination of nivolumab and ipilimumab across 37 subtypes of rare tumours included 33 patients with low-, intermediate- and high-grade NETs and NECs.
In the overall cohort of NETs patients, 70\% developed progressive disease within 6 months and median OS was at least 11 months. Interestingly, $42 \%$ of patients with high-grade NETs and NECs and $0 \%$ of patients with lowgrade NETs achieved a partial or complete response to treatment (Patel et al. 2019). In a phase II clinical trial involving 95 patients with well-differentiated NETs, the primary site was thoracic $(n=30)$, pancreatic (pNETs) $(n=33)$ and gastro-intestinal $(n=32)$ as well as patients with poorly differentiated gastroenteropancreatic NECs (GEP-NECs) $(n=21)$. The study analysed spartalizumab, a PD-1 inhibitor, and found that in the well-differentiated cohort, there were seven partial responses (7\%) and 55\% had stable disease, while $31 \%$ had progressive disease. The confirmed objective response rate was $7 \%$, and the disease control rate was 63\%. In the GEP-NECs cohort, the objective response rate was $5 \%$ and the disease control rate was 19\% (Chauhan et al. 2018). The previously mentioned studies show that treatment outcomes of ICIs in patients with NETs and NECs are heterogeneous. The NECs studies give signs that response to ICIs is possible. Currently, several studies are ongoing, investigating the value of ICIs for patients with NETs/NECs (Table 1). Now, we will discuss what potential factors are involved in the TME of NETs and NECs that relate to this heterogeneity and irresponsiveness to ICIs.

\section{Hallmarks of response to ICls and their presence in NETs and NECs}

In recent years, several factors that influence response to ICIs have been identified. These include the degree of 'tumour foreignness', T-cell inhibitory mechanisms, the immune cell infiltration and presence of checkpoints of the tumour and other factors in the TME (Blank et al. 2016, Chen \& Mellman 2017). Here, we describe several of these hallmarks of response specifically focusing on their relevance in NET and their targetability.

\section{Tumour foreignness}

Tumour cells are better recognized by the immune system when they are substantially different from normal cells. An altered antigen repertoire presented by the major histocompatibility complex-1 (MHC-1) is influenced by tumour mutational load and allows tumour cells to be recognized by $\mathrm{T}$ cells and presented by antigen presenting cells. Mutational load, also known as tumour (c) 2020 Society for Endocrinology Published by Bioscientifica Ltd. Printed in Great Britain 
Table 1 Ongoing trials involving ICls in NETs and NECs.

\begin{tabular}{l} 
Therapy \\
\hline Ipilimumab + nivolumab \\
Nivolumab + ipilimumab \\
Pembrolizumab \\
Pembrolizumab \\
Pembrolizumab \\
Pembrolizumab + lanreotide \\
Pembrolizumab + chemotherapy \\
Spartalizumab/ PDR001 \\
Pembrolizumab + talabostat mesylate \\
Avelumab \\
Avelumab \\
Avelumab \\
Avelumab \\
Nivolumab and temozolomide \\
Ipilimumab + nivolumab + cabozantinib \\
S-malate + cabozantinib \\
Durvalumab + tremelumumab
\end{tabular}

\begin{tabular}{c}
\hline Phase \\
\hline 2 \\
2 \\
2 \\
2 \\
2 \\
$1 \mathrm{~b} / 2$ \\
2 \\
2 \\
$1 \mathrm{~b} / 2$ \\
2 \\
2 \\
2 \\
$1 / 2$ \\
2 \\
2 \\
2
\end{tabular}

\begin{tabular}{l} 
Patient population \\
\hline Gl-cancer/NETs/reproductive \\
neoplasm \\
NF-GEP or NF-BP NETs \\
NECs \\
NETs \\
G3 NETs or NECs \\
GEP-NETs or pNETs \\
BP-NECs \\
NETs + NECs \\
Prostate NETs \\
NETs G2/3 \\
GEP-NECS \\
NECS \\
GEP- or BP-NECS \\
NECS \\
NECS \\
G1 + G2 GEP- or BP-NETs and \\
G3 GEP NET
\end{tabular}

\begin{tabular}{l}
\hline Estimated completion date \\
\hline Dec 2023 \\
Jan 2024 \\
Sep 2022 \\
Jan 2020 \\
Dec 2021 \\
Jun 2020 \\
Jun 2020 \\
Sep 2020 \\
Jun 2022 \\
Sep 2021 \\
Feb 2020 \\
Jan 2024 \\
Sep 2020 \\
Dec 2021 \\
Oct 2021 \\
Mar 2020 \\
\hline
\end{tabular}

\begin{tabular}{l} 
NCT number \\
\hline NCT02923934 \\
NCT03420521 \\
NCT03190213 \\
NCT02939651 \\
NCT03290079 \\
NCT03043664 \\
NCT03135055 \\
NCT02955069 \\
NCT03910660 \\
NCT03278379 \\
NCT03147404 \\
NCT03352934 \\
NCT03278405 \\
NCT03728361 \\
NCT04079712
\end{tabular}

NCT03095274

BP, bronchopulmonary; G1, grade 1; G2, grade 2; G3, grade 3; Gl, gastrointestinal; NCT, clincaltrials.gov identifier; NECs, neuroendocrine carcinomas; NETs, neuroendocrine tumours; NF, non-functioning; pNETs, pancreatic neuroendocrine tumours.

mutational burden (TMB), is defined as the total number of mutations in the DNA of tumour cells. ICIs have changed clinical practice for lung cancer and melanoma, which are tumour types with some of the highest tumour mutational burdens (TMB) (median TMB 7.2 and 13.5 mutations $/ \mathrm{Mb}$, respectively). In comparison, a mean TMB of 5.4 was shown for pNETs (Salem et al. 2017, Büttner et al. 2019). High TMB is likely related to a proportionally higher burden of immunogenic cancer-specific 'neoantigens'; however, these 'neoantigen' proteins must be processed and expressed (van Allen et al. 2015, Cogdill et al. 2017). RNA-based studies have identified gene expression signatures linked to immune infiltration within the TME that correlate with neoantigen load (Brown et al. 2014, Rooney et al. 2015). The value of the gene expression signature is that tumours having these mutational epitopes can be identified and a prediction can be made which patients are likely to benefit from checkpoint blockade.

Another way in which the degree of tumour foreignness can increase is through impaired DNA mismatch repair (MMR). Mutations or silencing of genes involved in DNA base pairing results in a DNA chain of altered length and highly repeated sequences (microsatellites), a phenomenon called microsatellite instability (MSI). In May 2017, the FDA approved pembrolizumab for patients with unresectable or metastatic MSI-high (MSI-H) or mismatch repair deficient solid tumours that have progressed following prior treatment (Masuda et al. 2011, Le et al. 2015). Two studies including 89 small-intestine NETs (siNETs) and 35 pNETs patients analysed DNA MMR and MSI. Both studies showed that, in NETs, defects in DNA MMR were rare and tumours were microsatellite stable (Kidd et al. 2005, Arnason et al. 2011). A different study investigating DNA MMR and MSI in NECs and mixed adenoneuroendocrine carcinomas (MANECs) included 53 NECs and 36 MANECs patients from several sites of origin. This study demonstrated that $12.4 \%$ of patients with either NECs or MANECs were MSI (Sahnane et al. 2015). A study comparing well-differentiated NETs $(n=24)$ with poorly differentiated NECs $(n=14)$ showed that progression of NETs was associated with MSI (Furlan et al. 2004). The tumour foreignness of NETs is low, since NETs generally do not differ much from normal neuroendocrine cells. Due to lower E-cadherin levels, neuroendocrine cells may spread and thus metastasize before acquiring multiple mutations and thus have a relatively low degree of tumour foreignness at time of metastatic disease (Waldum et al. 2014). These studies show signs that NECs may not develop from normal neuroendocrine cells and this should be further investigated. A subgroup of patients with NENs possess hallmarks that are associated with potential clinical benefit from treatment with ICIs. Higher grade NETs could have a different TME, higher TMB and are more often DNA MMR deficient.
C) 2020 Society for Endocrinology Published by Bioscientifica Ltd. Printed in Great Britain 


\section{General immune status and the influence of the microbiome}

An impaired general immune status has shown correlations in the effectivity of ICIs due to a reduced ability to mount or maintain a systemic tumour-specific T-cell response (Blank et al. 2016). Furthermore, specific compositions of the gut microbiome have been shown to influence the anti-tumour response and response to ICIs. This influence of the gut microbiome on anti-tumour immunity was shown in a preclinical melanoma mouse model. In this study, melanoma growth in mice harbouring distinct commensal microbiota showed a good response to ICIs targeting PD-L1, whereas the other group did not. More interestingly, after faecal cohousing or after faecal transfer of the responding mice into the mice who did not respond, the response to ICIs improved markedly (Sivan et al. 2015). The influence of specific gut microbiota on the response to ICIs was confirmed in a clinical study including 112 melanoma patients that were treated with PD-1 targeting ICIs. In this study, it was demonstrated that oral and gut microbiome significantly differed in diversity and composition of responders vs non-responders to ICIs (Gopalakrishnan et al. 2018). Interventions manipulating the gut microbiome during immune-based cancer therapeutics aiming to improve response rates are currently in clinical trials. In a study using mice xenografted with the NET cell line BON, germ-free mice were compared to mice colonized with human gut microbiota to identify potential mechanisms through which microbial products such as short-chain fatty acids could augment tryptophan hydroxylase-1 (TPH1) and serotonin synthesis. (Parekh et al. 1994, Siddique et al. 2009). The study found that gut microbes promote colonic serotonin production through an effect of short-chain fatty acids on enterochromaffin cells (Reigstad et al. 2015). Currently, no data on the gut microbiome of patients with NETs and NECs treated with ICIs are available. It is potentially of interest to investigate whether manipulation of the gut microbiome in patients with NETs could lead to a better response to ICIs.

\section{Immune cell infiltration}

Immune cell infiltration in the TME is one of the most essential characteristics for an appropriate anti-tumour immune response to develop. Patients with tumours with a high degree of tumour infiltrating lymphocytes (TILs) have a better prognosis and response to ICIs than patients with tumours with a low degree TILs (Harlin et al. 2009, Gajewski et al. 2013, Gajewski 2015). Important characteristics of TILs are density, distribution and type of TILs. The most favourable profile consists of both CD4 $\mathrm{T}$ cells and CD8 $\mathrm{T}$ cells because of their complementary role in the anti-tumour immune response. It is commonly accepted that antibody responses against the often poorly immunogenic tumour antigens necessitate strong $\mathrm{T}$ cell help and that IL-2 produced by CD4 T cells may be required for growth and proliferation of CD8 $\mathrm{T}$ cells. These events have been shown to be necessary for prolonged anti-tumour immunity and complete tumour regression (Gerloni \& Zanetti 2005). CD8 T cells can have both effector and memory functions, thereby contributing to therapeutic efficacy of ICIs. (Farhood et al. 2019).

The TME of tumours have been classified into 'hot', 'altered (excluded and immunosuppressed)' and 'cold' (Galon \& Bruni 2019). The 'hot' immune TME is characterized by a high degree of T-cell and cytotoxic T-cell infiltration (also known as a high Immunoscore) together with checkpoint expression (PD-1, PD-L1 and CTLA-4, T-cell immunoglobulin mucin receptor 3 (TIM3) and lymphocyte activation gene 3 (LAG3) or otherwise impaired T-cell functions. The 'altered-immunosuppressed TME is characterized by poor T-cell- and cytotoxic T-cell infiltration (considered as intermediate Immunoscore), presence of soluble inhibitory mediators, presence of immune suppressive cells and presence of T-cell checkpoints. The 'altered-excluded' immune TME is characterized by no T-cell infiltration inside the tumour bed; accumulation of $\mathrm{T}$ cells at tumour borders (considered as intermediate Immunoscore), activation of oncogenic pathways, epigenetic regulation and reprogramming of the TME, aberrant tumour vasculature and/or stroma, and hypoxia. The 'cold' TME is characterized by absence of $\mathrm{T}$ cells within and around the tumour edges (also known as low Immunoscore) and failed T-cell priming (low mutational burden, poor antigen presentation and intrinsic insensitivity to T-cell killing) (Galon \& Bruni 2019) (Fig. 1).

Tumour infiltration by T cells, NK cells, mast cells, macrophages and dendritic cells in the TME of NETs has been studied. In an observational study investigating 87 patients with NETs, it was found that, in primary intermediate-grade NETs, a dense CD3+T-cell infiltrate was associated with a median recurrence free survival of 128 months compared with 61 months for those with low levels of intratumoural T cells. In the same study, 39 NETs patients with liver metastases (NETLMs) included both low- and intermediate grade primary NETLMs and revealed that the degree of infiltration by $\mathrm{CD} 3+, \mathrm{CD} 4+$ and CD8+ did not predict OS, whereas a low level of infiltrating regulatory $\mathrm{T}$ cells (Tregs) was a predictor of prolonged OS 

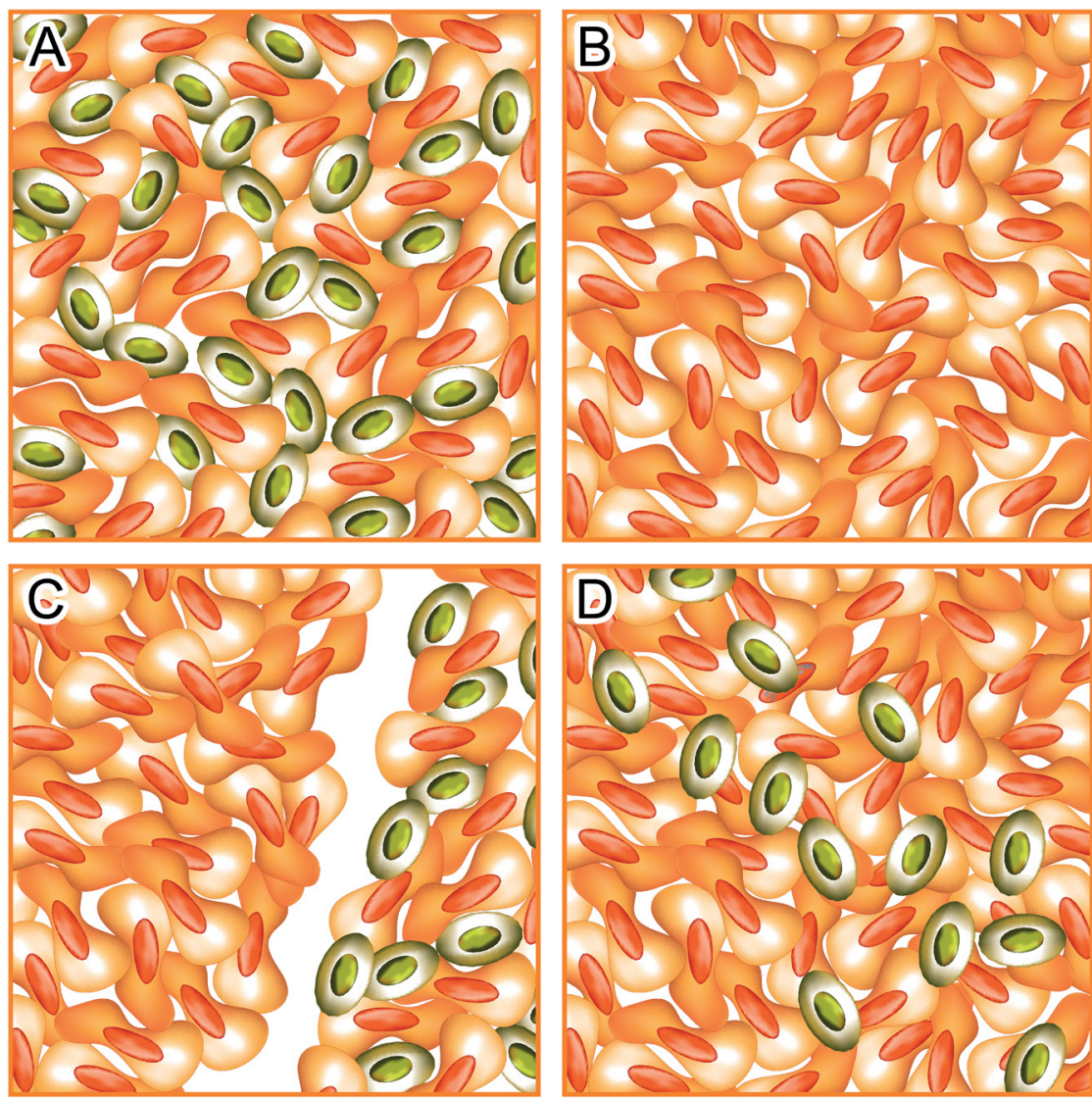

\section{Figure 1}

Schematic representation of the immune TME. Four different types of tumour cell infiltration by immune cells like CD3+ and CD8+ T cells can be distinguished. The different types relate to both level and distribution of T-cell infiltration and consist of 'hot' (panel A), 'altered' (can be both immunosuppressed (panel B) or excluded (panel C)) and 'cold' (panel D). These tumour phenotypes are characterized by high (panel A), intermediate (panel B and C) and low Immunoscore (panel D), respectively, which relates to response to immune checkpoint inhibitors.
(Katz et al. 2010). In a different study, it was demonstrated that TILs were more abundant in pNETs than in siNETs and that there was no clear association between immune checkpoint marker expression, immune cell infiltrates, and specific mutational profile within each tumour type (da Silva et al. 2018). A different retrospective study including 51 patients with grade 1 and 2 NETs analysed the presence of $\mathrm{T}$ cells in the immune microenvironment of NETs. The study found that T-cells were present in 15 of the 45 samples, varying between 1 and 10\% of T-cells per high power field. $\mathrm{T}$ cells were most frequently found within the stroma of NETs of the jejunum/ileum (in 7 of 22 samples), which were all serotonin producing NETs (De Hosson et al. 2020).

In a retrospective study in patients with low-grade carcinoid tumours $(n=57)$ and patients with high-grade lung NECs $(n=185)$, a marked difference in mean CD8+ T-cell infiltration was found (12 vs 92, respectively) (Kasajima et al. 2018). Ferrata et al. showed that, by combining CD3+ cells and PD-L1 status in patients with grade 3 NETs, they identified the immune ignorant phenotype of tumour microenvironment as being the most common phenotype (Ferrata et al. 2019). A retrospective study including 33 patients with NECs of the digestive tract analysed the infiltration in the tumour immune microenvironment and found that $\mathrm{CD}^{+} \mathrm{T}$-cell infiltration was observed in 23 patients (69.7\%), with nine patients detected as high infiltration; $\mathrm{CD}^{+}{ }^{+}$cytotoxic T-cell infiltration was observed in nine patients $(27.3 \%)$ and all were detected as low infiltration (Xing et al. 2020). The previously mentioned data suggests that the immune TME of lower-grade NETs are infiltrated by T cells but that higher-grade NETs/NECs have an even higher infiltration.

\section{Presence of checkpoints}

Tumours express PD-L1 to evade immune mediated killing and PD-L1 expression is, therefore, a logical requirement for response to ICIs treatment. A study of 75 patients with NSCLC treated with a combination of antiCTLA-4 and anti-PD-1 found that PD-L1 staining is an independent predictor of response (Hellmann et al. 2018). (c) 2020 Society for Endocrinology Published by Bioscientifica Ltd. Printed in Great Britain 
Another double-blind, phase 3 clinical trial (KEYNOTE 189) involving 616 patients with metastatic non-squamous NSCLC reported that PD-L1 levels may be predictive of response to pembrolizumab plus chemotherapy in the setting of first-line treatment for patients with NSCLC (Gandhi et al. 2018). Interestingly, some studies also found that the expression of PD-L1 on particular cells may be an important factor, as PD-L1 can be expressed on both TILs and tumour cells (Tang et al. 2018). In independent cohorts of patients with melanoma and patients with urothelial carcinoma, it was found that PD-L1 expression on TILs, but not on tumour cells themselves, was associated with response to anti-PD-1 or anti-PD-L1 treatment (Herbst et al. 2014, Rosenberg et al. 2016, Mariathasan et al. 2018, Havel et al. 2019). PD-1 and PD-L1 expression in NETs is more common in poorly differentiates NETs than in welldifferentiated NETs. The expression (patterns) of PD-1 and PD-L1 in multiple NETs studies is shown in Table 2 (Kim et al. 2016, Roberts et al. 2017, da Silva et al. 2018, Kasajima et al. 2018, Lamarca et al. 2018, Wang et al. 2018, 2019, Ferrata et al. 2019). In general, PD-L1 expression remains an important but imperfect predictor of ICIs response. This imperfection might be due to the fact that different PD-L1 detection assays are used and that there are no standardized criteria for the assessment of PD-L1 positive tumours. Furthermore, even when PD-L1 expression is correlated with response, there are many patients with low to no detectable PD-L1 expression who experience durable clinical benefit (Sunshine \& Taube 2015). Therefore, PD-L1 expression itself is not a standalone biomarker for therapeutic decisions in clinical practice for all tumour types. PD-L1 expression appears to be higher in NECs, but its role in prognosticating response to ICIs remains to be elucidated.

\section{Absence of tumour associated macrophages}

Tumour inflammation-associated factors can promote tumour progression. Theinfiltration of immunosuppressive factors in the TME of tumour cells influences the response to ICIs (Mantovani et al. 1992, Balkwill \& Mantovani et al. 2001). Tumour-associated macrophages (TAMs) and their derived cytokines IL-6, TNF, IL- $1 \beta$ and IL-23 are generally recognized as dominant tumour-promoting forces and have a possible influence on the response to ICIs treatment. (Vitale et al. 2019) In a study analysing the presence of PD-1 on TAMs in both murine and human models, it was demonstrated that TAMs PD-1 expression negatively correlates with phagocytic potency against tumour cells (Gordon et al. 2017).

In a retrospective study in 57 patients with grade 3 NETs, the presence of TAMs was reported to be 59\% which coincided with a low CD8+ T-cell infiltration in the TME (Ferrata et al. 2019). In accordance with this, a study in 104 patients with pNETs reported a negative correlation between TAMs and CD8+ presence in the TME (Cai et al. 2019). Several studies investigating the influence of macrophages in the TME of pNETs concluded that the presence of macrophages in the TME was positively correlated with tumour recurrence risk, higher grade,

Table 2 PD-1 and PD-L1 expression on tumour cells and TILs.

\begin{tabular}{|c|c|c|c|c|c|c|c|}
\hline Tumour location & PD-1/PD-L1 & Samples & TILs (in \%) & Tumour (in \%) & $\begin{array}{l}\text { Cut-off used for } \\
\text { interpretation of } \\
\text { positive screening }\end{array}$ & Metastasis? & Author \\
\hline GEP NETS & PD-1 & 120 & 56 & $X$ & Not reported & No & Wang et al. 2019 \\
\hline G1 or G2 siNETs & $\begin{array}{l}\text { PD-1 } \\
\text { PD-L1 }\end{array}$ & 70 & $\begin{array}{l}22.8 \\
24.3\end{array}$ & $\begin{array}{l}X \\
12.8\end{array}$ & $\geq 5 \%$ & No & Lamarca et al. 2018 \\
\hline pNETs & PD-L1 & 159 & $45^{a}$ & $45^{a}$ & $\begin{array}{l}\text { Tumour: } \geq 5 \% \\
\text { TILs: }>1 \%\end{array}$ & No & Wang et al. 2018 \\
\hline $\begin{array}{l}\text { siNETs } \\
\text { pNETs }\end{array}$ & PD-L1 & $\begin{array}{l}64 \\
31\end{array}$ & $\begin{array}{l}X \\
X\end{array}$ & $\begin{array}{l}0 \\
7.4\end{array}$ & $\geq 5 \%$ & No & da Silva et al. 2018 \\
\hline $\begin{array}{l}\text { G2 GEP NETs } \\
\text { G3 GEP NECS }\end{array}$ & PD-L1 & $\begin{array}{l}15 \\
17\end{array}$ & $\begin{array}{l}0 \\
41\end{array}$ & $X$ & $\geq 1 \%$ & Liver & Kim et al. 2016 \\
\hline NECS & $\begin{array}{l}\text { PD-1 } \\
\text { PD-L1 }\end{array}$ & 37 & $\begin{array}{l}63 \\
27\end{array}$ & $\begin{array}{l}16 \\
14\end{array}$ & $>1 \%$ & No & Roberts et al. 2017 \\
\hline $\begin{array}{l}\text { BP NETs } \\
\text { BP NECs }\end{array}$ & PD-L1 & $\begin{array}{r}57 \\
185\end{array}$ & $\begin{array}{l}0 \\
38\end{array}$ & $\begin{array}{l}0 \\
11\end{array}$ & $\geq 1 \%$ & No & Kasajima et al. 2018 \\
\hline G3 NET & PD-L1 & 57 & 24.5 & 15.7 & $\geq 1 \%$ & No & Ferrata et al. 2019 \\
\hline
\end{tabular}

aThis study has specified the expression of both TILs and tumour and not separately.

BP, bronchopulmonary; G1, grade 1; G2, grade 2; G3, grade 3; GEP, gastroenteropancreatic; NECs, neuroendocrine carcinomas; NETs, neuroendocrine tumours; PD-1, programmed cell death-1; PD-L1, programmed cell death ligand-1; pNETs, pancreatic neuroendocrine tumours; siNETs, small intestine neuroendocrine tumours; TILs, tumour infiltrating lymphocytes; $\mathrm{X}$, not reported. 
and metastatic disease (Pyonteck et al. 2012, Wei et al. 2014, Cai et al. 2019). These findings support the hypothesis that TAMs play a role in the immunosuppressive TME of NETs by production of cytokines and chemokines.

Due to the abundant presence of TAMs and its possible effect on the immunosuppressive TME in NETs, an interesting target for future therapies might be inhibition of the CD47/signal regulatory protein alpha (SIRP $\alpha$ ) axis. This axis is active in both solid and haematological tumour cells which normally helps these tumours evade macrophages (Weiskopf 2017). Normally, CD47 is used by tumour cells to evade recognition by macrophages and, therefore, CD47/SIRP $\alpha$ inhibition enables recognition of tumour cells by macrophages and subsequently activating the innate immune system (don't eat me signal) (Weiskopf 2017).

In NETs patients, somatostatin analogues have widely demonstrated significant improvement in symptomatic relief and tumour control growth by a complex mechanism of action including inhibition of cell survival, angiogenesis and immunomodulation (Alonso-Gordoa et al. 2015). Interferon-alpha (IFN-a) had long been established as potential treatment modality of patients with NETs. Already in 1983 it was demonstrated that IFN counteracts the NETs-secreted vasoactive substances (Öberg et al. 1983). The efficacy of immunotherapy depends on intact IFN signalling for the promotion of both direct (tumour cell inhibition) and indirect (antitumour immune responses) effects (Kline et al. 2008). A study analysed gene expression profiles (GEPs) using RNA from baseline tumour samples of pembrolizumab-treated patients with melanoma and demonstrated that immunerelated signatures correlate with clinical benefit. The T-cellinflamed GEP contained IFN- $\gamma$-responsive genes related to antigen presentation, chemokine expression, cytotoxic activity, and adaptive immune resistance. These features were necessary, but not always sufficient, for clinical benefit of ICIs treatment. The T-cell-inflamed GEPs have been developed into a clinical-grade assay which is also known as IFN- $\gamma$ signature (Ayers et al. 2017). In a more recent study, IFN- $\gamma$ presence in the TME was shown to be a predictive biomarker for response to ICIs in NSCLC and melanoma (Karachaliou et al. 2018). This archival study in 17 patients with NSCLC treated with nivolumab revealed that patients with low IFN- $\gamma$ in the TME had a median PFS of 2.0 months, whereas patients with high levels of IFN- $\gamma$ had a PFS of 5.1 months. The same study showed that, in the 21 melanoma patients treated with pembrolizumab, patients with low IFN- $\gamma$ in the TME had a median PFS of 1.9 months and that this was 5.0 months in patients with a high level of IFN- $\gamma$. A phase Ib/II study analysed the combination of pembrolizumab with pegylated-interferon (PEG-IFN) alfa $2 \mathrm{~b}$ in 43 patients with stage IV melanoma. The study demonstrated that IFN-type 1 (IFN-1) signalling is involved in the anti-tumour immune response in patients with melanoma. At a median follow-up duration of 25 months, the objective response rate was $60.5 \%$ and $46.5 \%$ of patients had ongoing responses. The median PFS duration was 11.0 months in the whole cohort and median PFS was not reached in patients with a response. The median OS duration was not reached (Davar et al. 2018, Romero 2019). A currently recruiting study, including patients with metastasized or unresectable NETs with a low proliferation rate, treats patients with a combination of cyclophosphamide and IFN-a to evaluate whether this treatment regimen decreases the rate of circulatory Tregs (ClinicalTrials.gov Identifier: NCT02838342). In the future, IFN treatment combined with ICIs should be investigated as a combination treatment and its possible benefit in NETs patients.

\section{Absence of inhibitory tumour metabolism}

Cancer cells are characterized by reprogrammed metabolism, allowing cancer cells to survive in nutrient poor environments. For example, even in the presence of sufficient oxygen, pyruvate is mainly converted to lactate, a process known as aerobic glycolysis. In both cancer and normal cells, the conversion of pyruvate into lactate takes place due to lactate dehydrogenase (LDH). High serum LDH concentrations correlate strongly with poor response to ICI in melanoma. Furthermore, lactate and low local pH can impair crucial T-cell functions (Blank et al. 2016).

The mammalian target of rapamycin (mTOR) signalling pathway has been shown to be a promising target for cancer therapy and is registered for treatment of NETs patients. mTOR is known to have immunosuppressive functions, as it is approved for solid organ transplantation medicine to prevent rejection of the transplanted organ (host vs graft disease). The activated mTOR kinase in a complex with raptor (mTORC1) leads to the phosphorylation of ribosomal S6 kinase 1 (S6K1) and eukaryotic initiation factor $4 \mathrm{E}$ binding protein 1 (4E-BP1), two key proteins that regulate protein translation of several proteins necessary for cellular proliferation and growth that have shown antitumor activity in two phase 2 studies involving patients with pNETs (Yao et al. 2008, 2010). Both rapamycin and everolimus bind immunophilin FK506binding protein 12 and inhibit mTOR signalling (Moreno et al. 2008). A phase 3 clinical trial in 410 patients with 
advanced low-grade or intermediate-grade pNETs analysed the effect of everolimus in comparison with placebo (Yao et al. 2011). This study demonstrated that median PFS was 11 months in patients receiving everolimus and 4.6 moths in patients receiving placebo. Estimates of the proportion of patients who were alive and progression-free at 18 months was $34 \%$ with everolimus as compared with $9 \%$ with placebo. In a recent pre-clinical study with mice that have renal cell carcinoma, the combination of anti-PD-L1 ICIs and everolimus was investigated. The study found that the combination of everolimus with anti-PD-L1 ICIs significantly reduced tumour burden compared with the everolimus alone treatment, increasing TILs and the ratio of cytotoxic CD8 ${ }^{+} \mathrm{T}$ cells to TILs (Hirayama et al. 2016).

In cancer cells, $>95 \%$ of tryptophan is catabolized via the kynurenine pathway by IDO, generating kynurenines (Pschowski et al. 2017). Kynurenines are known for their suppression of $\mathrm{T}$ cells and induction of apoptosis of $\mathrm{T}$ cells. Overall, IDO-induced tryptophan depletion might trigger an immunosuppressive TME in tumours via depletion, anergy, and apoptosis of T cells. Thus, IDO-induction plays an important role in the development of immunological tolerance and IDO-induced immunosuppression is used by solid malignancies to protect themselves from immune recognition and cytotoxicity - a fact that is recognized as a key tumour escape mechanism (Moffett \& Namboodiri 2003, Puccetti \& Grohmann 2007, Platten et al. 2012, Pschowski et al. 2017). Remarkably, in a phase 3 study analysing the effectivity of pembrolizumab and epacadostat (IDO-inhibitor) in patients with melanoma, it was demonstrated that there was no benefit in terms of PFS or OS (Long et al. 2018).

An interesting study performed by Opitz et al. shows that TDO is also frequently activated in cancer, predominantly when IDO is not activated (Opitz et al. 2011). The tryptophan-to-kynurenine metabolic pathway in tumour cells also uses TDO for the generation of kynurenine (Wardhani et al. 2019). TDO itself plays a role in cancer-cell migration which is a characteristic of TDO which IDO has never been shown to do (Prendergast 2011). This points towards functional differences between the enzymes even though both being able to generate kynurenine. Kynurenine is reported to be an endogenous ligand of the aryl hydrocarbon receptor (AHR) which plays a role in the signalling pathway of TDO to AHR that promotes malignant growth of the tumour. Kynurenine was also demonstrated to play a role in the generation of Tregs. Due to the role of Tregs in the immunosuppressive TME of tumours, kynurenines contribute to immune evasion by binding to AHR (Prendergast et al. 2010).
Next to the function of AHR in Tregs, AHR also negatively influences the immunogenicity of dendritic cells which is an important influential factor in the modulation of inflammation and immunity, therefore, suggesting the influence of IDO/TDO-kynurenine-AHR signalling pathway in the microenvironment of tumours (Gajewski et al. 2006, Cogdill et al. 2017, Havel et al. 2019, Heidegger et al. 2019). Due to the effects of IDO and TDO in cancer cells, an interesting therapeutic option in the future might be the use of an IDO/TDO dual inhibitor in combination with ICIs. A phase 1 study is currently investigating the safety and tolerability of an IDO1/TDO dual inhibitor in 30 patients with advanced solid tumours (ClinicalTrials.gov Identifier: NCT03208959). This might also be a promising combination with ICIs in NETs.

The reason for the immunosuppressive TME in serotonin-producing NETs is that they use tryptophan for the secretion of serotonin. This can lead to the utilization of $60 \%$ of the tryptophan pool for serotonin synthesis in the tumour (Fleischmajer \& Hyman 1961, Castiello \& Lynch 1972, Bender 1983). This derangement may then result in tryptophan depletion (Bouma et al. 2016). $\mathrm{T}$ cells activated under tryptophan-deficient conditions are able to synthesize protein, enter the cell cycle, and progress normally through the initial stages of G1, including upregulation of IL-2 receptor and synthesis of IL-2. However, in the absence of tryptophan, cell-cycle progression is halted at a mid-G1 arrest point, thereby diminishing T cell proliferation (Munn et al. 1999). Both the secretion of serotonin and generation of kynurenines lead to tryptophan depletion which in itself creates an immunosuppressive TME in NETs. Furthermore, since IDO and TDO are both active in NETs, higher levels of kynurenine also lead to an immunosuppressive TME and these pathways likely influence the TME in NETs (Fig. 2).

\section{Discussion and future directives}

NETs and NECs are tumours that can originate anywhere in the body. A growing amount of available data on the TME of these tumours creates new therapeutic opportunities. Immunotherapy has changed cancer treatment approaches in several tumour types and efforts are ongoing to explore the efficacy of immune checkpoint inhibitors in patients with NETs and NECs. Expression of PD-L1, lymphocyte infiltration, mismatch repair deficiency, tumour mutational load, and neoantigen load are predictors of response to immune checkpoint blockade. NETs generally exhibit a 'cold' tumour immune 


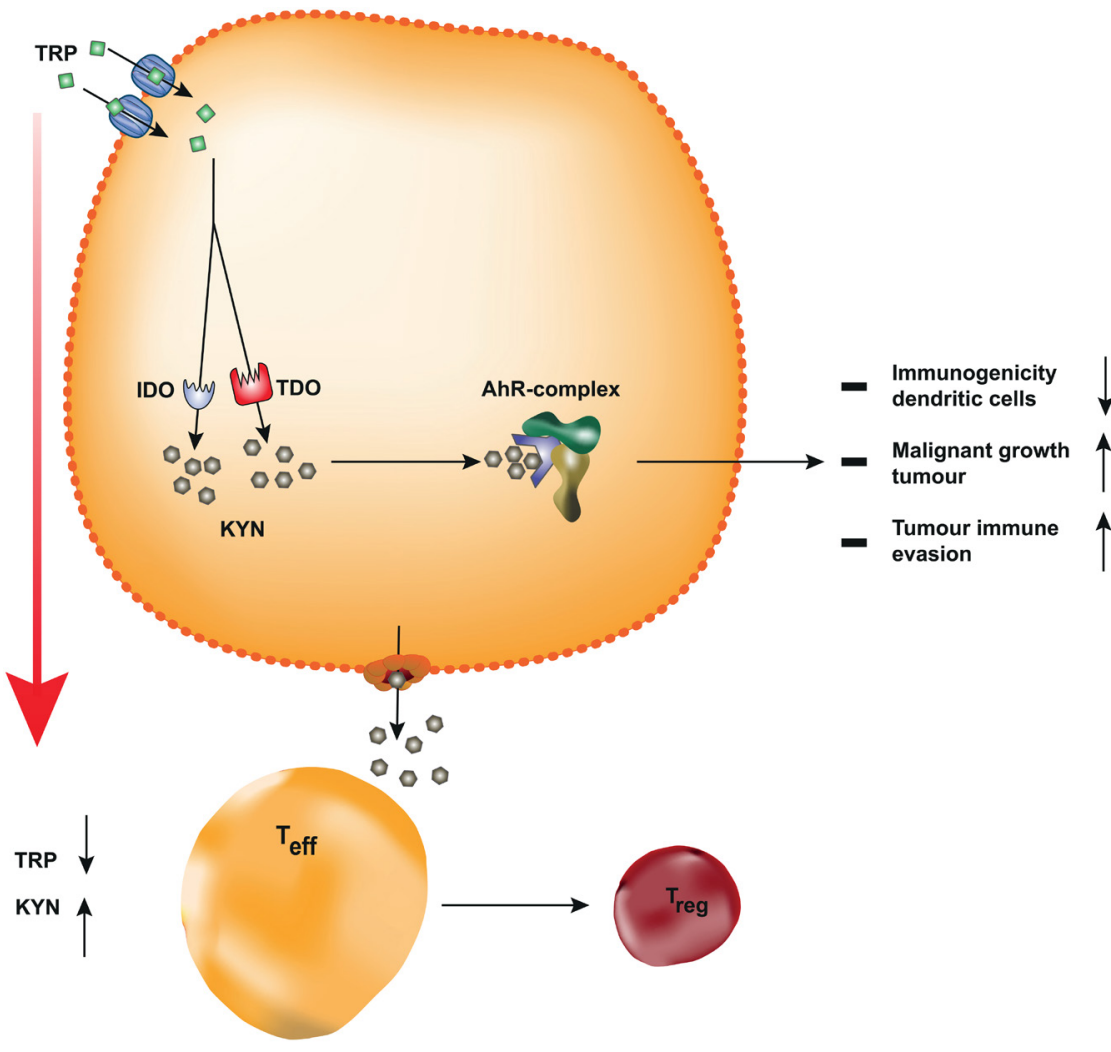

\section{Figure 2}

Schematic representation of the IDO/TDO pathway and its influence on the TME of NETs and NECs. IDO and TDO catalyze the conversion of tryptophan into its derivative kynurenine. As a consequence, tryptophan depletion triggers amino acid-deprivation-associated apoptosis of effector T cells. Accumulated kynurenine acts as a ligand for the aryl hydrocarbon receptor (AhR). In a manner that is dependent on AhR, kynurenine promotes the regulatory T-cell phenotype, further contributing to the suppression of antitumor immune responses. Finally, kynurenine potentiates autocrine signaling through AhR on cancer cells themselves, promoting degradation of the extracellular matrix and invasion (Pavlova cell metabolism). microenvironment lacking several of these favourable factors. Lymphocyte infiltration is often seen in NETs, but it is unclear whether TILs are effectively primed by tumour neoantigens, given the relatively low proportion of cases positive for PD-L1. Most NETs appear to be mismatch repair proficient, and the mutational burden of such malignancies is relatively low compared to NSCLC and melanoma. In contrast, given their extensive mutational load and denser immune infiltration, NECs are likely more suitable targets for immunotherapy (Cives et al. 2019).

Several pre-clinical and clinical studies have investigated the response to several types of ICIs in both NETs and NECs. Based on these limited data, we know that patients with NETs do not show robust responses to immune checkpoint blockade antibodies (Mehnert et al. 2017, Ott et al. 2019, Strosberg et al. 2019). Only a small part of patients with NET respond to ICIs. In particular, patients with higher grade NETs and NECs showed better responses ranging from 7 to 42\% (Chauhan et al. 2018, Fottner et al. 2019, Patel et al. 2019).

The expression of IDO and TDO in a proportion of patients with NETs may be one of the mechanisms responsible for this 'cold' immune microenvironment. Especially serotonin-producing NETs express IDO and TDO. These patients often have low tryptophan levels, since tryptophan is the sole precursor of both peripherally and centrally produced serotonin. Furthermore, IDO catalyses tryptophan into kynurenines and thereby creates an immunosuppressive TME. This suggests that IDO-mediated immune suppression is most prominent in patients with low tryptophan levels and that these patients might therefore be interesting candidates for treatment with ICIs combined with IDO inhibitors. TDO catalyses the conversion of tryptophan into its derivative kynurenine. Tryptophan depletion triggers amino aciddeprivation-associated apoptosis of effector $\mathrm{T}$ cells. Accumulated kynurenine acts as a ligand for AhR. In a manner that is dependent on AhR, kynurenine promotes the regulatory T-cell phenotype, further contributing to the suppression of antitumor immune responses. TDO inhibitors might therefore be an interesting therapeutic option to decrease the immunosuppressive TME of NETs because inhibition of TDO results in decreased kynurenine, resulting in immune activation. Due to the abundant presence of TAMs, and their inverse relation to T-cell infiltration in the TME of NETs, combination of CD47 inhibitors with ICIs might be an interesting option for investigation in future studies. An analysis in 22 refractory B-cell non-Hodgkin lymphoma (NHL) patients demonstrated an objective 50\% response and a complete response of $36 \%$ when combining ICIs that inhibit CD47 and an antibody inhibiting CD20 (Advani et al. 2018). 
Although the overall presence of PD-L1 is low in tumours of patients with NETs, the presence of PD-L1 does not necessarily correlate with response to ICIs. The same has been shown in melanoma and NSCLC, therefore, the focus should be taken off PD-L1 as a standalone biomarker for therapeutic decisions in clinical practice. In future studies, the value of PD-1, CTLA-4 and other potential biomarkers such as, for example, the microbiome composition should be further explored.

\section{Conclusion}

In conclusion, immunotherapy and, in particular, ICIs have transformed treatment of several types of cancer. NETs responses to ICI in clinical trials have overall been disappointing. In this review, we presented several key aspects of the TME in NETs which may influence response rate to ICIs. These include a low infiltration of CD8+ T cells in NETs and a high infiltration of immunosuppressive cells such as Tregs and macrophages which results in an immunosuppressive TME. Possible reasons for this immunosuppressive TME are the low concentration of IFN and the production of serotonin, IDO and TDO and the subsequent production of kynurenines. This also presents us with possible combinational treatment options incorporating inhibitors of these factors together with ICIs.

\section{Declaration of interest}

The authors declare that there is no conflict of interest that could be perceived as prejudicing the impartiality of the research reported.

\section{Funding}

This research did not receive any specific grant from any funding agency in the public, commercial or not-for-profit sector.

\section{References}

Advani R, Flinn I, Popplewell L, Forero A, Bartlett NL, Ghosh N, Kline J, Roschewski M, LaCasce A, Collins GP, et al. 2018 CD47 blockade by Hu5F9-G4 and rituximab in non-Hodgkin's lymphoma. New England Journal of Medicine 379 1711-1721. (https://doi.org/10.1056/ NEJMoa1807315)

Alonso-Gordoa T, Capdevila J \& Grande E 2015 GEP-NETs UPDATE: Biotherapy for neuroendocrine tumours. European Journal of Endocrinology 172 R31-R46. (https://doi.org/10.1530/EJE-14-0354)

Arnason T, Sapp HL, Rayson D, Barnes PJ, Drewniak M, Nassar BA \& Huang WY 2011 Loss of expression of DNA mismatch repair proteins is rare in pancreatic and small intestinal neuroendocrine tumors. Archives of Pathology and Laboratory Medicine 135 1539-1544. (https://doi.org/10.5858/arpa.2010-0560-OA)

Ayers M, Lunceford J, Nebozhyn M, Murphy E, Loboda A, Kaufman DR, Albright A, Cheng JD, Kang SP, Shankaran V, et al. 2017 IFN- $\gamma$-related mRNA profile predicts clinical response to PD-1 blockade. Journal of Clinical Investigation 127 2930-2940. (https://doi.org/10.1172/ JCI91190)

Balkwill F \& Mantovani A 2001 Inflammation and cancer: back to Virchow? Lancet 357 539-545. (https://doi.org/10.1016/S01406736(00)04046-0)

Bender DA 1983 Biochemistry of tryptophan in health and disease. Molecular Aspects of Medicine 6 101-197. (https://doi. org/10.1016/0098-2997(83)90005-5)

Blank CU, Haanen JB, Ribas A \& Schumacher TN 2016 The 'cancer immunogram.' Science 352 658-660. (https://doi.org/10.1126/ science.aaf2834)

Bouma G, van Faassen M, Kats-Ugurlu G, de Vries EGE, Kema IP \& Walenkamp AME 2016 Niacin (vitamin B3) supplementation in patients with serotonin-producing neuroendocrine tumor. Neuroendocrinology 103 489-494. (https://doi.org/10.1159/000440621)

Brown SD, Warren RL, Gibb EA, Martin SD, Spinelli JJ, Nelson BH \& Holt RA 2014 Neo-antigens predicted by tumor genome metaanalysis correlate with increased patient survival. Genome Research 24 743-750. (https://doi.org/10.1101/gr.165985.113)

Büttner R, Longshore JW, López-Ríos F, Merkelbach-Bruse S, Normanno N, Rouleau E \& Penault-Llorca F 2019 Implementing TMB measurement in clinical practice: considerations on assay requirements. ESMO Open 4 e000442. (https://doi.org/10.1136/ esmoopen-2018-000442)

Cai L, Michelakos T, Deshpande V, Arora KS, Yamada T, Ting DT, Taylor MS, Fernandez-del Castillo CF, Warshaw AL, Lillemoe KD, et al. 2019 Role of tumor associated macrophages in the clinical course of pancreatic neuroendocrine tumors (PanNETs). Clinical Cancer Research 25 2644-2655. (https://doi.org/10.1158/1078-0432. CCR-18-1401)

Castiello RJ \& Lynch PJ 1972 Pellagra and the carcinoid syndrome. Archives of Dermatology 105 574-577. (https://doi.org/10.1001/ archderm.1972.01620070046016)

Chambers CA, Kuhns MS, Egen JG \& Allison JP 2001 CTLA-4-mediated inhibition in regulation of $\mathrm{T}$ cell responses: mechanisms and manipulation in tumor immunotherapy. Annual Review of Immunology 19 565-594. (https://doi.org/10.1146/annurev. immunol.19.1.565)

Chauhan A, Horn M, Magee G, Hodges K, Evers M, Arnold S \& Anthony L 2018 Immune checkpoint inhibitors in neuroendocrine tumors: a single institution experience with review of literature. Oncotarget 9 8801-8809. (https://doi.org/10.18632/oncotarget.23753)

Chen DS \& Mellman I 2017 Elements of cancer immunity and the cancer-immune set point. Nature $\mathbf{5 4 1} 321-330$. (https://doi. org/10.1038/nature21349)

Cives M, Pelle E, Quaresmini D, Rizzo FM, Tucci M \& Silvestris F 2019 The tumor microenvironment in neuroendocrine tumors: biology and therapeutic implications. Neuroendocrinology 109 83-99. (https:// doi.org/10.1159/000497355)

Cogdill AP, Andrews MC \& Wargo JA 2017 Hallmarks of response to immune checkpoint blockade. British Journal of Cancer 117 1-7. (https://doi.org/10.1038/bjc.2017.136)

da Silva A, Bowden M, Zhang S, Masugi Y, Thorner AR, Herbert ZT, Zhou CW, Brais L, Chan JA, Hodi FS, et al. 2018 Characterization of the neuroendocrine tumor immune microenvironment. Pancreas $\mathbf{4 7}$ 1123-1129. (https://doi.org/10.1097/MPA.0000000000001150)

Dasari A, Shen C, Halperin D, Zhao B, Zhou S, Xu Y, Shih T \& Yao JC 2017 Trends in the incidence, prevalence, and survival outcomes in patients With neuroendocrine tumors in the United States. JAMA Oncology 3 1335-1342. (https://doi.org/10.1001/ jamaoncol.2017.0589) 
Davar D, Wang H, Chauvin JM, Pagliano O, Fourcade JJ, Ka M, Menna C, Rose A, Sander C, Borhani AA, et al. 2018 Phase Ib/II study of pembrolizumab and pegylated-interferon alfa- $2 \mathrm{~b}$ in advanced melanoma. Journal of Clinical Oncology 36 JCO1800632. (https://doi.org/10.1200/JCO.18.00632)

de Hosson LD, Takkenkamp TJ, Kats-Ugurlu G, Bouma G, Bulthuis M, de Vries EGE, Faassen M, Kema IP \& Walenkamp AME 2020 Neuroendocrine tumours and their microenvironment. Cancer Immunology, Immunotherapy 69 1449-1459. (https://doi.org/10.1007/ s00262-020-02556-1)

Dorfman DM, Brown JA, Shahsafaei A \& Freeman GJ 2006 Programmed death-1 (PD-1) is a marker of germinal center-associated T cells and angioimmunoblastic T-cell lymphoma. American Journal of Surgical Pathology 30 802-810. (https://doi.org/10.1097/01. pas.0000209855.28282.ce)

Emens LA, Ascierto PA, Darcy PK, Demaria S, Eggermont AMM, Redmond WL, Seliger B \& Marincola FM 2017 Cancer immunotherapy: opportunities and challenges in the rapidly evolving clinical landscape. European Journal of Cancer 81 116-129. (https://doi.org/10.1016/j.ejca.2017.01.035)

Farhood B, Najafi M \& Mortezaee K 2019 CD8+ cytotoxic T lymphocytes in cancer immunotherapy: a review. Journal of Cellular Physiology 234 8509-8521. (https://doi.org/10.1002/jcp.27782)

Ferrata M, Schad A, Zimmer S, Musholt TJ, Bahr K, Kuenzel J, Becker S, Springer E, Roth W, Weber MM, et al. 2019 PD-L1 expression and immune cell infiltration in gastroenteropancreatic (GEP) and nonGEP neuroendocrine neoplasms With high proliferative activity. Frontiers in Oncology 9 343. (https://doi.org/10.3389/fonc.2019.00343)

Fleischmajer R \& Hyman AB 1961 Clinical significance of derangements of tryptophan metabolism. A review of pellagra, carcinoid and $\mathrm{H}$ disease. Archives of Dermatology 84 563-573. (https://doi.org/10.1001/ archderm.1961.01580160027003)

Fottner C, Apostolidis L, Ferrata M, Krug S, Michl P, Schad A, Roth W, Jaeger D, Galle PR \& Weber MM 2019 A phase II, open label, multicenter trial of avelumab in patients with advanced, metastatic high-grade neuroendocrine carcinomas NEC G3 (WHO 2010) progressive after first-line chemotherapy (AVENEC). Journal of Clinical Oncology 37 (15 Suppl) 4103-4103. (https://doi.org/10.1200/ JCO.2019.37.15_suppl.4103)

Furlan D, Cerutti R, Uccella S, La Rosa S, Rigoli E, Genasetti A \& Capella C 2004 Different molecular profiles characterize welldifferentiated endocrine tumors and poorly differentiated endocrine carcinomas of the gastroenteropancreatic tract. Clinical Cancer Research 10 947-957. (https://doi.org/10.1158/1078-0432.CCR1068-3)

Gajewski TF 2015 The next hurdle in cancer immunotherapy: overcoming the non-T-cell-inflamed tumor microenvironment. Seminars in Oncology 42 663-671. (https://doi.org/10.1053/j. seminoncol.2015.05.011)

Gajewski TF, Meng Y \& Harlin H 2006 Immune suppression in the tumor microenvironment. Journal of Immunotherapy 29 233-240. (https://doi.org/10.1097/01.cji.0000199193.29048.56)

Gajewski TF, Woo SR, Zha Y, Spaapen R, Zheng Y, Corrales L \& Spranger S 2013 Cancer immunotherapy strategies based on overcoming barriers within the tumor microenvironment. Current Opinion in Immunology 25 268-276. (https://doi.org/10.1016/j. coi.2013.02.009)

Galon J \& Bruni D 2019 Approaches to treat immune hot, altered and cold tumours with combination immunotherapies. Nature Reviews Drug Discovery 18 197-218. (https://doi.org/10.1038/s41573-018-0007-y)

Gandhi L, Rodríguez-Abreu D, Gadgeel S, Esteban E, Felip E, de Angelis F, Domine M, Clingan P, Hochmair MJ, Powell SF, et al. 2018 Pembrolizumab plus chemotherapy in metastatic non-small-cell lung cancer. New England Journal of Medicine 378 2078-2092. (https://doi. org/10.1056/NEJMoa1801005)
Gerloni M \& Zanetti M 2005 CD4 T cells in tumor immunity. Springer Seminars in Immunopathology 27 37-48. (https://doi.org/10.1007/ s00281-004-0193-z)

Gopalakrishnan V, Spencer CN, Nezi L, Reuben A, Andrews MC, Karpinets TV, Prieto PA, Vicente D, Hoffman K, Wei SC, et al. 2018 Gut microbiome modulates response to anti-PD-1 immunotherapy in melanoma patients. Science 359 97-103. (https://doi.org/10.1126/ science.aan4236)

Gordon SR, Maute RL, Dulken BW, Hutter G, George BM, McCracken MN, Gupta R, Tsai JM, Sinha R, Corey D, et al. 2017 PD-1 expression by tumour-associated macrophages inhibits phagocytosis and tumour immunity. Nature 545 495-499. (https:// doi.org/10.1038/nature22396)

Greenwald RJ, Freeman GJ \& Sharpe AH 2005 The B7 family revisited. Annual Review of Immunology 23 515-548. (https://doi.org/10.1146/ annurev.immunol.23.021704.115611)

Harlin H, Meng Y, Peterson AC, Zha Y, Tretiakova M, Slingluff C, McKee M \& Gajewski TF 2009 Chemokine expression in melanoma metastases associated with CD8+ T-cell recruitment. Cancer Research 69 3077-3085. (https://doi.org/10.1158/0008-5472.CAN-08-2281)

Havel JJ, Chowell D \& Chan TA 2019 The evolving landscape of biomarkers for checkpoint inhibitor immunotherapy. Nature Reviews Cancer 19 133-150. (https://doi.org/10.1038/s41568-019-0116-x)

Heidegger S, Wintges A, Stritzke F, Bek S, Steiger K, Koenig PA, Göttert S, Engleitner T, Öllinger R, Nedelko T, et al. 2019 RIG-I activation is critical for responsiveness to checkpoint blockade. Science Immunology 4 eaau8943. (https://doi.org/10.1126/sciimmunol. aau8943)

Hellmann MD, Nathanson T, Rizvi H, Creelan BC, Sanchez-Vega F, Ahuja A, Ni A, Novik JB, Mangarin LMB, Abu-Akeel M, et al. 2018 Genomic features of response to combination immunotherapy in patients with advanced non-small-cell lung cancer. Cancer Cell $\mathbf{3 3}$ 843.e4-852.e4. (https://doi.org/10.1016/j.ccell.2018.03.018)

Herbst RS, Soria JC, Kowanetz M, Fine GD, Hamid O, Gordon MS, Sosman JA, McDermott DF, Powderly JD, Gettinger SN, et al. 2014 Predictive correlates of response to the anti-PD-L1 antibody MPDL3280A in cancer patients. Nature 515 563-567. (https://doi. org/10.1038/nature14011)

Hirayama Y, Gi M, Yamano S, Tachibana H, Okuno T, Tamada S, Nakatani T \& Wanibuchi H 2016 Anti-PD-L1 treatment enhances antitumor effect of everolimus in a mouse model of renal cell carcinoma. Cancer Science 107 1736-1744. (https://doi.org/10.1111/ cas.13099)

Karachaliou N, Gonzalez-Cao M, Crespo G, Drozdowskyj A, Aldeguer E, Gimenez-Capitan A, Teixido C, Molina-Vila MA, Viteri S, de Los Llanos Gil M, et al. 2018 Interferon gamma, an important marker of response to immune checkpoint blockade in non-small cell lung cancer and melanoma patients. Therapeutic Advances in Medical Oncology 10 1758834017749748. (https://doi. org/10.1177/1758834017749748)

Kasajima A, Ishikawa Y, Iwata A, Steiger K, Oka N, Ishida H, Sakurada A, Suzuki H, Kameya T, Konukiewitz B, et al. 2018 Inflammation and PD-L1 expression in pulmonary neuroendocrine tumors. EndocrineRelated Cancer 25 339-350. (https://doi.org/10.1530/ERC-17-0427)

Katz SC, Donkor C, Glasgow K, Pillarisetty VG, Gönen M, Espat NJ, Klimstra DS, D'Angelica MI, Allen PJ, Jarnagin W, et al. 2010 T cell infiltrate and outcome following resection of intermediate-grade primary neuroendocrine tumours and liver metastases. HPB $\mathbf{1 2}$ 674-683. (https://doi.org/10.1111/j.1477-2574.2010.00231.x)

Kidd M, Eick G, Shapiro MD, Camp RL, Mane SM \& Modlin IM 2005 Microsatellite instability and gene mutations in transforming growth factor-beta type II receptor are absent in small bowel carcinoid tumors. Cancer 103 229-236. (https://doi.org/10.1002/cncr.20750)

Kim JY, Hong SM \& Ro JY 2017 Recent updates on grading and classification of neuroendocrine tumors. Annals of Diagnostic https://erc.bioscientifica.com

https://doi.org/10.1530/ERC-20-0113
C) 2020 Society for Endocrinology Published by Bioscientifica Ltd. Printed in Great Britain 
Pathology 29 11-16. (https://doi.org/10.1016/j.

anndiagpath.2017.04.005)

Kim ST, Ha SY, Lee S, Ahn S, Lee J, Park SH, Park JO, Lim HY, Kang WK, Kim KM, et al. 2016 The impact of PD-L1 expression in patients with metastatic GEP-NETs. Journal of Cancer 7 484-489. (https://doi. org $/ 10.7150 /$ jca.13711)

Kline J, Brown IE, Zha YY, Blank C, Strickler J, Wouters H, Zhang L \& Gajewski TF 2008 Homeostatic proliferation plus regulatory T-cell depletion promotes potent rejection of B16 melanoma. Clinical Cancer Research 14 3156-3167. (https://doi.org/10.1158/1078-0432. CCR-07-4696)

Lamarca A, Nonaka D, Breitwieser W, Ashton G, Barriuso J, McNamara MG, Moghadam S, Rogan J, Mansoor W, Hubner RA, et al. 2018 PD-L1 expression and presence of TILs in small intestinal neuroendocrine tumours. Oncotarget 9 14922-14938. (https://doi. org/10.18632/oncotarget.24464)

Larkin J, Chiarion-Sileni V, Gonzalez R, Grob JJ, Rutkowski P, Lao CD, Cowey CL, Schadendorf D, Wagstaff J, Dummer R, et al. 2019 Fiveyear survival with combined nivolumab and ipilimumab in advanced melanoma. New England Journal of Medicine $\mathbf{3 8 1}$ 1535-1546. (https://doi.org/10.1056/NEJMoa1910836)

Le DT, Uram JN, Wang H, Bartlett BR, Kemberling H, Eyring AD, Skora AD, Luber BS, Azad NS, Laheru D, et al. 2015 PD-1 blockade in tumors with mismatch-repair deficiency. New England Journal of Medicine 372 2509-2520. (https://doi.org/10.1056/NEJMoa1500596)

Long GV, Dummer R, Hamid O, Gajewski T, Caglevic C, Dalle S, Arance A, Carlino MS, Grob J-J, Kim TM, et al. 2018 Epacadostat (E) plus pembrolizumab (P) versus pembrolizumab alone in patients (pts) with unresectable or metastatic melanoma: results of the phase 3 ECHO-301/KEYNOTE-252 study. Journal of Clinical Oncology 36 (15 Suppl) 108. (https://doi.org/10.1200/JCO.2018.36.15_ suppl.108)

Luchini C, Bibeau F, Ligtenberg MJL, Singh N, Nottegar A, Bosse T, Miller R, Riaz N, Douillard JY, Andre F, et al. 2019 ESMO recommendations on microsatellite instability testing for immunotherapy in cancer, and its relationship with PD-1/PD-L1 expression and tumour mutational burden: a systematic reviewbased approach. Annals of Oncology 30 1232-1243. (https://doi. org/10.1093/annonc/mdz116)

Mantovani A, Bottazzi B, Colotta F, Sozzani S \& Ruco L 1992 The origin and function of tumor-associated macrophages. Immunology Today 13 265-270. (https://doi.org/10.1016/0167-5699(92)90008-U)

Mariathasan S, Turley SJ, Nickles D, Castiglioni A, Yuen K, Wang Y, Kadel III EE, Koeppen H, Astarita JL, Cubas R, et al. 2018 TGF $\beta$ attenuates tumour response to PD-L1 blockade by contributing to exclusion of T cells. Nature $554544-548$. (https://doi.org/10.1038/ nature25501)

Masuda K, Banno K, Yanokura M, Kobayashi Y, Kisu I, Ueki A, Ono A, Asahara N, Nomura H, Hirasawa A, et al. 2011 Relationship between DNA mismatch repair deficiency and endometrial cancer. Molecular Biology International 2011 256063. (https://doi. org/10.4061/2011/256063)

Mehnert JM, Rugo HS, O’Neil BH, Santoro A, Schellens JHM, Cohen RB, Doi T, Ott PA, Pishvaian MJ, Puzanov I, et al. 2017 Pembrolizumab for patients with PD-L1-positive advanced carcinoid or pancreatic neuroendocrine tumors: results from the KEYNOTE-028 study. Annals of Oncology 28 142-157. (https://doi.org/10.1093/annonc/ $\mathrm{mdx} 368$ )

Moffett JR \& Namboodiri MA 2003 Tryptophan and the immune response. Immunology and Cell Biology 81 247-265. (https://doi. org/10.1046/j.1440-1711.2003.t01-1-01177.x)

Moreno A, Akcakanat A, Munsell MF, Soni A, Yao JC \& Meric-Bernstam F 2008 Antitumor activity of rapamycin and octreotide as single agents or in combination in neuroendocrine tumors. EndocrineRelated Cancer 15 257-266. (https://doi.org/10.1677/ERC-07-0202)
Motzer RJ, Tannir NM, McDermott DF, Arén Frontera O, Melichar B, Choueiri TK, Plimack ER, Barthélémy P, Porta C, George S, et al. 2018 Nivolumab plus ipilimumab versus sunitinib in advanced renal-cell carcinoma. New England Journal of Medicine $\mathbf{3 7 8}$ 1277-1290. (https://doi.org/10.1056/NEJMoa1712126)

Öberg K, Funa K \& Alm G 1983 Effects of leukocyte interferon on clinical symptoms and hormone levels in patients with mid-gut carcinoid tumors and carcinoid syndrome. New England Journal of Medicine 309 129-133. (https://doi.org/10.1056/

NEJM198307213090301)

Opitz CA, Litzenburger UM, Sahm F, Ott M, Tritschler I, Trump S, Schumacher T, Jestaedt L, Schrenk D, Weller M, et al. 2011 An endogenous tumour-promoting ligand of the human aryl hydrocarbon receptor. Nature $\mathbf{4 7 8}$ 197-203. (https://doi.org/10.1038/ nature10491)

Ott PA, Bang YJ, Piha-Paul SA, Razak ARA, Bennouna J, Soria JC, Rugo HS, Cohen RB, O'Neil BH, Mehnert JM, et al. 2019 T-cellinflamed gene-expression profile, programmed death ligand 1 expression, and tumor mutational burden predict efficacy in patients treated with pembrolizumab across 20 cancers: KEYNOTE-028. Journal of Clinical Oncology 37 318-327. (https://doi.org/10.1200/ JCO.2018.78.2276)

Parekh D, Ishizuka J, Townsend CM, Haber B, Beauchamp RD, Karp G, Kim SW, Rajaraman S, Greeley G \& Thompson JC 1994 Characterization of a human pancreatic carcinoid in vitro: morphology, amine and peptide storage, and secretion. Pancreas 9 83-90. (https://doi.org/10.1097/00006676-199401000-00013)

Patel SP, Othus M, Chae YK, Giles F, Hayward J, McLeod C, Chen HX, Sharon E, Mayerson E, Ryan CW, et al. 2019 SWOG 1609 (Dart): a phase II basket trial of dual anti-CTLA-4 and anti-PD-1 blockade in rare tumors. Journal of Clinical Oncology 37 (15 Suppl) TPS2658. (https://doi.org/10.1200/JCO.2019.37.15_suppl.TPS2658)

Pavel M, Baudin E, Couvelard A, Krenning E, Öberg K, Steinmüller T, Anlauf M, Wiedenmann B, Salazar R \& Barcelona Consensus Conference Participants 2012 Enets consensus guidelines for the management of patients with liver and other distant metastases from neuroendocrine neoplasms of foregut, midgut, hindgut, and unknown primary. Neuroendocrinology 95 157-176. (https://doi. org/10.1159/000335597)

Phan AT, Kunz PL \& Reidy-Lagunes AT 2015 New and emerging treatment options for gastroenteropancreatic neuroendocrine tumors. Clinical Advances in Hematology and Oncology 13 (5 Supplement 5) 1-18.

Platten M, Wick W \& van den Eynde BJ 2012 Tryptophan catabolism in cancer: beyond IDO and tryptophan depletion. Cancer Research 72 5435-5440. (https://doi.org/10.1158/0008-5472.CAN-12-0569)

Prendergast GC 2011 Cancer: why tumours eat tryptophan. Nature $\mathbf{4 7 8}$ 192-194. (https://doi.org/10.1038/478192a)

Prendergast GC, Metz R \& Muller AJ 2010 Towards a genetic definition of cancer-associated inflammation: role of the IDO pathway. American Journal of Pathology 176 2082-2087. (https://doi. org/10.2353/ajpath.2010.091173)

Pschowski R, Pape UF, Fusch G, Fischer C, Jann H, Baur A, Arsenic R, Wiedenmann B, von Haehling S, Pavel M, et al. 2017 Increased activity of the immunoregulatory enzyme indoleamine-2,3dioxygenase with consecutive tryptophan depletion predicts death in patients with neuroendocrine neoplasia. Neuroendocrinology 104 135-144. (https://doi.org/10.1159/000445191)

Puccetti P \& Grohmann U 2007 IDO and regulatory T cells: a role for reverse signalling and non-canonical NF-kB activation. Nature Reviews Immunology 7 817-823. (https://doi.org/10.1038/nri2163)

Pyonteck SM, Gadea BB, Wang HW, Gocheva V, Hunter KE, Tang LH \& Joyce JA 2012 Deficiency of the macrophage growth factor CSF-1 disrupts pancreatic neuroendocrine tumor development. Oncogene $\mathbf{3 1}$ 1459-1467. (https://doi.org/10.1038/onc.2011.337) (c) 2020 Society for Endocrinology Published by Bioscientifica Ltd. Printed in Great Britain 
Raimondi G, Shufesky WJ, Tokita D, Morelli AE \& Thomson AW 2006 Regulated compartmentalization of programmed cell death-1 discriminates CD4+CD25+ resting regulatory $\mathrm{T}$ cells from activated $\mathrm{T}$ cells. Journal of Immunology 176 2808-2816. (https://doi.org/10.4049/ jimmunol.176.5.2808)

Reichel J, Chadburn A, Rubinstein PG, Giulino-Roth L, Tam W, Liu Y, Gaiolla R, Eng K, Brody J, Inghirami G, et al. 2015 Flow sorting and exome sequencing reveal the oncogenome of primary Hodgkin and Reed-Sternberg cells. Blood 125 1061-1072. (https://doi.org/10.1182/ blood-2014-11-610436)

Reigstad CS, Salmonson CE, Rainey JF, Szurszewski JH, Linden DR, Sonnenburg JL, Farrugia G \& Kashyap PC 2015 Gut microbes promote colonic serotonin production through an effect of shortchain fatty acids on enterochromaffin cells. FASEB Journal 29 1395-1403. (https://doi.org/10.1096/fj.14-259598)

Roberts JA, Gonzalez RS, Das S, Berlin J \& Shi C 2017 Expression of PD-1 and PD-L1 in poorly differentiated neuroendocrine carcinomas of the digestive system: a potential target for anti-PD-1/PD-L1 therapy. Human Pathology 70 49-54. (https://doi.org/10.1016/j. humpath.2017.10.003)

Romero D 2019 Interferon enhances immune-checkpoint inhibition. Nature Reviews Clinical Oncology 16 6-6. (https://doi.org/10.1038/ s41571-018-0128-6)

Rooney MS, Shukla SA, Wu CJ, Getz G \& Hacohen N 2015 Molecular and genetic properties of tumors associated with local immune cytolytic activity. Cell 160 48-61. (https://doi.org/10.1016/j. cell.2014.12.033)

Rosenberg JE, Hoffman-Censits J, Powles T, van der Heijden MS, Balar AV, Necchi A, Dawson N, O'Donnell PH, Balmanoukian A, Loriot Y, et al. 2016 Atezolizumab in patients with locally advanced and metastatic urothelial carcinoma who have progressed following treatment with platinum-based chemotherapy: a single-arm, multicentre, phase 2 trial. Lancet 387 1909-1920. (https://doi. org/10.1016/S0140-6736(16)00561-4)

Rudd CE, Taylor A \& Schneider H 2009 CD28 and CTLA-4 coreceptor expression and signal transduction. Immunological Reviews 229 12-26. (https://doi.org/10.1111/j.1600-065X.2009.00770.x)

Sahnane N, Furlan D, Monti M, Romualdi C, Vanoli A, Vicari E, Solcia E, Capella C, Sessa F \& la Rosa S 2015 Microsatellite unstable gastrointestinal neuroendocrine carcinomas: a new clinicopathologic entity. Endocrine-Related Cancer 22 35-45. (https://doi.org/10.1530/ ERC-14-0410)

Salem ME, Xiu J, Weinberg BA, El-Deiry WS, Weiner LM, Gatalica Z, Liu Z, el Ghazaly H, Xiao N, Hwang JJ, et al. 2017 Characterization of tumor mutation burden (TMB) in gastrointestinal (GI) cancers. Journal of Clinical Oncology 35 530. (https://doi.org/10.1200/ JCO.2017.35.4_suppl.530)

Schmidt D \& Wiedenmann B 2018 Extremely long survival under combined immunotherapy in a metastatic functional neuroendocrine neoplasia patient. Neuroendocrinology 106 381-388. (https://doi.org/10.1159/000486417)

Seto T, Sam D \& Pan M 2019 Mechanisms of primary and secondary resistance to immune checkpoint inhibitors in cancer. Medical Sciences 7 14. (https://doi.org/10.3390/medsci7020014)

Siddique ZL, Drozdov I, Floch J, Gustafsson BI, Stunes K, Pfragner R, Kidd M \& Modlin IM 2009 KRJ-I and BON cell lines: defining an appropriate enterochromaffin cell neuroendocrine tumor model. Neuroendocrinology 89 458-470. (https://doi.org/10.1159/000209330)

Sivan A, Corrales L, Hubert N, Williams JB, Aquino-Michaels K, Earley ZM, Benyamin FW, Man Lei YM, Jabri B, Alegre ML, et al. 2015 Commensal Bifidobacterium promotes antitumor immunity and facilitates anti-PD-L1 efficacy. Science 350 1084-1089. (https:// doi.org/10.1126/science.aac4255)

Strosberg JR, Mizuno N, Doi T, Grande E, Delord J-P, Shapira-Frommer R, Bergsland EK, Shah MH, Fakih M, Takahashi S, et al. 2019 Pembrolizumab treatment of advanced neuroendocrine tumors: results from the phase II KEYNOTE-158 study. Journal of Clinical Oncology 37 (4 Suppl) 190-190. (https://doi.org/10.1200/ JCO.2019.37.4_suppl.190)

Sunshine J \& Taube JM 2015 PD-1/PD-L1 inhibitors. Current Opinion in Pharmacology 23 32-38. (https://doi.org/10.1016/j.coph.2015.05.011)

Tang H, Liang Y, Anders RA, Taube JM, Qiu X, Mulgaonkar A, Liu X, Harrington SM, Guo J, Xin Y, et al. 2018 PD-L1 on host cells is essential for PD-L1 blockade-mediated tumor regression. Journal of Clinical Investigation 128 580-588. (https://doi.org/10.1172/ JCI96061)

van Allen EM, Miao D, Schilling B, Shukla SA, Blank C, Zimmer L, Sucker A, Hillen U, Geukes Foppen MHG, Goldinger SM, et al. 2015 Genomic correlates of response to CTLA-4 blockade in metastatic melanoma. Science 350 207-211. (https://doi.org/10.1126/science. aad0095)

Vansteenkiste J, Wauters E, Reymen B, Ackermann CJ, Peters S \& de Ruysscher D 2019 Current status of immune checkpoint inhibition in early-stage NSCLC. Annals of Oncology 30 1244-1253. (https:// doi.org/10.1093/annonc/mdz175)

Vetizou M, Pitt JM, Daillere R, Lepage P, Waldschmitt N, Flament C, Rusakiewicz S, Routy B, Roberti MP, Duong CPM, et al. 2015 Anticancer immunotherapy by CTLA-4 blockade relies on the gut microbiota. Science 350 1079-1084. (https://doi.org/10.1126/science. aad1329)

Vitale I, Manic G, Coussens LM, Kroemer G \& Galluzzi L 2019 Macrophages and metabolism in the tumor microenvironment. Cell Metabolism 30 36-50. (https://doi.org/10.1016/j.cmet.2019.06.001)

Waldum HL, Aase S, Kvetnoi I, Brenna E, Sandvik AK, Syversen U, Johnsen G, Vatten L \& Polak JM 1998 Neuroendocrine differentiation in human gastric carcinoma. Cancer 83 435-444. (https://doi.org/10.1002/(SICI)1097-0142(19980801)83:3<435::AIDCNCR11>3.0.CO;2-X)

Waldum HL, Ringnes E, Nordbø H, Sørdal Ø, Nordrum IS \& Hauso Ø 2014 The normal neuroendocrine cells of the upper gastrointestinal tract lack E-cadherin. Scandinavian Journal of Gastroenterology 49 974-978. (https://doi.org/10.3109/00365521.2014.909275)

Wang H, Li Z, Dong B, Sun W, Yang X, Liu R, Zhou L, Huang X, Jia L \& Lin D 2018 Prognostic significance of PD-L1 expression and CD8+ T cell infiltration in pulmonary neuroendocrine tumors. Diagnostic Pathology 13 30. (https://doi.org/10.1186/s13000-018-0712-1)

Wang C, Yu J, Fan Y, Ma K, Ning J, Hu Y, Niu W, Dong X, Wu Y, Li E, et al. 2019 The clinical significance of PD-L1/PD-1 expression in gastroenteropancreatic neuroendocrine neoplasia. Annals of Clinical and Laboratory Science 49 448-456.

Ward FJ, Dahal LN \& Abu-Eid R 2018 On the road to immunotherapy - prospects for treating head and neck cancers with checkpoint inhibitor antibodies. Frontiers in Immunology 9 2182. (https://doi. org/10.3389/fimmu.2018.02182)

Wardhani LO, Matsushita M, Iwasaki T, Kuwamoto S, Nonaka D, Nagata K, Kato M, Kitamura Y \& Hayashi K 2019 Expression of the IDO1/TDO2-AhR pathway in tumor cells or the tumor microenvironment is associated with Merkel cell polyomavirus status and prognosis in Merkel cell carcinoma. Human Pathology 84 52-61. (https://doi.org/10.1016/j.humpath.2018.09.003)

Weber MM \& Fottner C 2018 Immune checkpoint inhibitors in the treatment of patients with neuroendocrine neoplasia. Oncology Research and Treatment 41 306-312. (https://doi. org/10.1159/000488996)

Wei IH, Harmon CM, Arcerito M, Cheng DF, Minter RM \& Simeone DM 2014 Tumor-associated macrophages are a useful biomarker to predict recurrence after surgical resection of nonfunctional pancreatic neuroendocrine tumors. Annals of Surgery 260 1088-1094. (https://doi.org/10.1097/SLA.0000000000000262)

Weiskopf K 2017 Cancer immunotherapy targeting the CD47/SIRP $\alpha$ axis. European Journal of Cancer 76 100-109. (https://doi.org/10.1016/j. ejca.2017.02.013) https://erc bioscientifica com

https://doi.org/10.1530/ERC-20-0113
C) 2020 Society for Endocrinology Published by Bioscientifica Ltd. Printed in Great Britain 
Wolchok JD, Chiarion-Sileni V, Gonzalez R, Rutkowski P, Grob JJ, Cowey CL, Lao CD, Wagstaff J, Schadendorf D, Ferrucci PF, et al. 2017 Overall survival with combined nivolumab and ipilimumab in advanced melanoma. New England Journal of Medicine $\mathbf{3 7 7}$ 1345-1356. (https://doi.org/10.1056/NEJMoa1709684)

Xing J, Ying H, Li J, Gao Y, Sun Z, Li J, Bai C, Cheng Y \& Wu H 2020 Immune checkpoint markers in neuroendocrine carcinoma of the digestive system. Frontiers in Oncology 10 132. (https://doi. org/10.3389/fonc.2020.00132)

Yao JC, Lombard-Bohas C, Baudin E, Kvols LK, Rougier P, Ruszniewski P, Hoosen S, St Peter J, Haas T, Lebwohl D, et al. 2010 Daily oral everolimus activity in patients with metastatic pancreatic neuroendocrine tumors after failure of cytotoxic chemotherapy: a phase II trial. Journal of Clinical Oncology 28 69-76. (https://doi. org/10.1200/JCO.2009.24.2669)

Yao JC, Phan AT, Chang DZ, Wolff RA, Hess K, Gupta S, Jacobs C, Mares JE, Landgraf AN, Rashid A, et al. 2008 Efficacy of RAD001 (everolimus) and octreotide LAR in advanced low- to intermediategrade neuroendocrine tumors: results of a Phase II study. Journal of Clinical Oncology 26 4311-4318. (https://doi.org/10.1200/ JCO.2008.16.7858)

Yao JC, Shah MH, Ito T, Bohas CL, Wolin EM, van Cutsem E, Hobday TJ, Okusaka T, Capdevila J, de Vries EGE, et al. 2011 Everolimus for advanced pancreatic neuroendocrine tumors. New England Journal of Medicine 364 514-523. (https://doi.org/10.1056/ NEJMoa1009290)

Received in final form 10 June 2020

Accepted 25 June 2020

Accepted Manuscript published online 25 June 2020 (c) 2020 Society for Endocrinology Published by Bioscientifica Ltd. Printed in Great Britain 